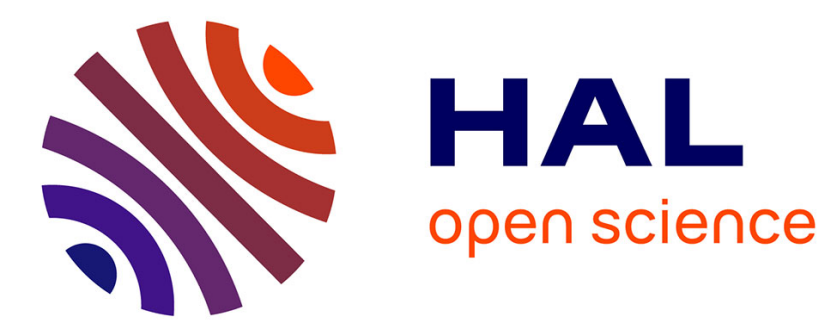

\title{
Optimal selection of organic solvents for biocompatible extraction of $\beta$-carotene from Dunaliella salina
}

\author{
M. Mojaat, A. Foucault, Jeremy Pruvost, J. Legrand
}

\section{To cite this version:}

M. Mojaat, A. Foucault, Jeremy Pruvost, J. Legrand. Optimal selection of organic solvents for biocompatible extraction of $\beta$-carotene from Dunaliella salina. Journal of Biotechnology, 2008, 133 (4), pp.433-441. 10.1016/j.jbiotec.2007.11.003 . hal-02534189

\section{HAL Id: hal-02534189 \\ https://hal.science/hal-02534189}

Submitted on 17 Apr 2020

HAL is a multi-disciplinary open access archive for the deposit and dissemination of scientific research documents, whether they are published or not. The documents may come from teaching and research institutions in France or abroad, or from public or private research centers.
L'archive ouverte pluridisciplinaire $\mathbf{H A L}$, est destinée au dépôt et à la diffusion de documents scientifiques de niveau recherche, publiés ou non, émanant des établissements d'enseignement et de recherche français ou étrangers, des laboratoires publics ou privés. 


\title{
Optimal selection of organic solvents for biocompatible extraction of $\beta$-carotene from Dunaliella salina
}

\author{
M. Mojaat, A. Foucault*, J. Pruvost, J. Legrand \\ Université de Nantes, CNRS, GEPEA UMR-CNRS 6144, Boulevard de l'Université, \\ CRTT-BP 406, 44602 Saint-Nazaire Cedex, France
}

Received 11 July 2007; received in revised form 20 October 2007; accepted 12 November 2007

\begin{abstract}
In the aim of $\beta$-carotene biocompatible extraction, toxicity of various pure solvents belonging to different homologous series has been investigated for Dunaliella salina. The results showed that solvents having $\log P_{\text {oct }}>5$ or having a molecular weight over $150 \mathrm{~g} / \mathrm{mol}$ can be considered biocompatible for this microalga. The membrane critical solvent concentration for each series of solvents has been calculated applying Osborne's model, showing that the aliphatic chlorinated hydrocarbon is the most toxic family studied. Mixtures of a biocompatible solvent (decane) with a toxic solvent $\left(\mathrm{CH}_{2} \mathrm{Cl}_{2}, \mathrm{MEK}, \mathrm{MTBE}\right)$ have been studied. The $\beta$-carotene extraction ability of $\mathrm{CH}_{2} \mathrm{Cl}_{2}$-decane mixture was found six times more efficient than with pure decane. It has been demonstrated that the extraction ability of solvent depends on its affinity with the product extracted and on its concentration incorporated in the cellular membrane.
\end{abstract}

Keywords: $\beta$-Carotene; Dunaliella salina; Biphasic systems extraction; Mixed solvents

\section{Introduction}

Microalgae are important sources of food and pharmaceutical additives such as colorants and antioxidants (León et al., 2001). Furthermore they are considered as potential producers of a large number of new natural products, as $\beta$-carotene. This molecule is used as food additive for its antioxidant and vitamin properties (Metting, 1996), and is added to numerous cosmetic and body-care products as a non-harmful colorant to improve the attractiveness of the product (Dufossé et al., 2005).

The $\beta$-carotene is a secondary pigment in photosynthetic organisms such as microalgae (León et al., 2003). Its main natural source is the extremophile green microalga Dunaliella salina, discovered in 1960. It can accumulate high concentrations of $\beta$ carotene (up to a concentration of $10 \%$ of dry weight) in oil globules in the cells (Ben-Amotz, 1982). Actually, more than $90 \%$ of commercialized $\beta$-carotene is chemically synthesized (León et al., 2003). Several industrial exploitations of Dunaliella are operational in Australia, Israel (Ben-Amotz, 1995), USA
(Borowitzka, 1999) and China (Raja et al., 2007). Table 1 summarizes several methods for $\beta$-carotene extraction from algae, where the $\beta$-carotene is extracted in organic solvents or edible oils, directly or after breaking cells by osmotic or mechanical shock.

However, $\beta$-carotene production using microalgae is limited by the slow growth rate of photosynthetic microorganisms (compared to bacteria or yeasts). So, if a method can be applied in which the produced biomass is re-used for the production of metabolites, this can be a new approach to improve the productivity of biosynthetic processes while producing continuously the $\beta$-carotene. In this case, a biphasic aqueous/organic system offers a solution in which both production and extraction occur simultaneously (Hejazi et al., 2003; León et al., 2003). A biocompatible organic solvent is in contact with the aqueous phase where the cells are carrying out the bioconversion (Hejazi and Wijffels, 2003); the product is continuously extracted into the organic phase due to a permeability effect of the solvent on cell membrane (Hejazi et al., 2002; Xu et al., 2004). However, a direct contact between microorganisms and a solvent may result in significant losses in biomass (Choi et al., 2000; Osborne et al., 1990). The selection of the solvent is of critical relevance (León et al., 1998) where it must satisfy certain requirements such as 
biocompatibility, maximum solubility for $\beta$-carotene and important extraction ability (Daugulis, 1988). Main constraint is that it must perform the product extraction with preservation of the cell viability. A significant amount of work has been done and published, focusing on this topic (Laane et al., 1987; Santhanam and Shreve, 1994; Hejazi et al., 2002; León et al., 2003). León et al. (2003) have studied some organic solvents and shown that the ability of decane and dodecane for biocompatible extraction of $\beta$-carotene is respectively about $20 \%$ and $10 \%$ of the maximum.

Biocompatibility and extraction ability of the organic phase is not easy to achieve simultaneously; several solutions have been proposed to minimize the solvent toxicity and make biocompatibility a less restrictive criterion. Mixtures of toxic but good extractive solvents with poor extractive but biocompatible ones (Bruce and Daugulis, 1991) are one of the solutions proposed to protect cells from solvent toxicity.

A method to predict the solvent ability to meet these strict requirements would be of great practical use, since experimental data are seldom available for a specific system, and there are hundreds of solvents from which to choose. We report in this paper a new strategy of solvent selection by providing new experimental information for the selection of appropriate organic solvents suited for the biocompatible extraction of $\beta$-carotene from Dunaliella salina, leading to a significant decrease of the amount of experimental work required.
Table 1

Methods for $\beta$-carotene extraction from Dunaliella salina ${ }^{\mathrm{a}}$

\begin{tabular}{ll}
\hline Breaking method & Extracting solvent \\
\hline Osmotic shock & $\begin{array}{l}\text { Ethanol, hexane, cyclohexane } \\
\text { and benzene } \\
\text { Halogenated, aliphatic or } \\
\text { aromatic hydrocarbon }\end{array}$ \\
Thermal treatment & $\begin{array}{l}\text { Edible oil } \\
\text { Super-critical } \mathrm{CO}_{2}\end{array}$ \\
Homogenization & $\begin{array}{l}\text { Hexane, cyclohexane and } \\
\text { petroleum ether }\end{array}$ \\
No additional breaking & Edible oil \\
Osmotic shock mechanical methods & Methylene chloride and ethanol \\
Thermal treatment & $\begin{array}{l}\text { Acetone, methanol and } \\
\text { di-ethylether }\end{array}$ \\
Strong solvent (methanol) & Mixture of one acid ester and oil \\
Strong solvent & \\
Thermal treatment and organic & \\
solvents &
\end{tabular}

${ }^{\mathrm{a}}$ From Hejazi et al. (2002).

\section{Materials and methods}

\subsection{Organism and culture conditions}

Dunaliella salina (CCAP 19/18) was gathered from the culture collection of IFREMER (Nantes, France). D. salina was cultivated in artificial medium composed of: $1.5 \mathrm{M} \mathrm{NaCl}, 10 \mathrm{mM}$ $\mathrm{KNO}_{3}, 0.4 \mathrm{mM} \mathrm{K \textrm {KH } _ { 2 } \mathrm { PO } _ { 4 } , 5 \mathrm { mM } \mathrm { MgSO }}, 185 \mu \mathrm{M} \mathrm{H} \mathrm{H}_{3} \mathrm{BO}_{3}$, $0.2 \mathrm{mM} \mathrm{CaCl}_{2}, 2 \mu \mathrm{M} \mathrm{FeCl}_{3}, 7 \mu \mathrm{M} \mathrm{MnCl}_{2}, 1 \mu \mathrm{M} \mathrm{ZnCl}_{2}, 1 \mu \mathrm{M}$ $\mathrm{CoCl}_{2}, 1 \mu \mathrm{M} \mathrm{CuCl}, 1 \mu \mathrm{M}\left(\mathrm{NH}_{4}\right)_{6} \mathrm{Mo}_{7} \mathrm{O}_{24}, 5 \mu \mathrm{M} \mathrm{Na} \mathrm{N}_{2} \mathrm{EDTA}$

Table 2

Physical properties of solvents investigated ${ }^{\mathrm{a}}$

\begin{tabular}{|c|c|c|c|}
\hline Solvents & Max. solubility in water $\left(\mathrm{mg}^{-1}\right)$ & Molecular weight $\left(\mathrm{g} \mathrm{mol}^{-1}\right)$ & $\log P_{\text {oct }}$ \\
\hline \multicolumn{4}{|c|}{ Aliphatic chlorinated hydrocarbons } \\
\hline Chloroform & $7.95 \times 10^{3}$ & 119.38 & 1.97 \\
\hline Dichloromethane & $13 \times 10^{3}$ & 84.93 & 1.25 \\
\hline Trichloroethane & $1.29 \times 10^{3}$ & 133.41 & 2.49 \\
\hline \multicolumn{4}{|l|}{ Aliphatic ketones } \\
\hline Acetone & $10^{6}$ & 58.08 & -0.24 \\
\hline Methyl ethyl ketone & $2.23 \times 10^{5}$ & 72.11 & 0.29 \\
\hline Methyl isobutyl ketone & 19 & 100.16 & 1.31 \\
\hline \multicolumn{4}{|l|}{ Aliphatic ethers } \\
\hline Methyl tert-butyl ether & $5.1 \times 10^{4}$ & 88.15 & 0.94 \\
\hline Diethyl ether & $6.04 \times 10^{4}$ & 74.12 & 0.89 \\
\hline Di-isopropyl ether & $8.8 \times 10^{3}$ & 102.18 & 1.52 \\
\hline \multicolumn{4}{|l|}{ Aliphatic alcohols } \\
\hline Pentanol & $22 \times 10^{3}$ & 88.15 & 1.51 \\
\hline Hexanol & $5.9 \times 10^{3}$ & 102.18 & 2.03 \\
\hline Heptanol & $3.27 \times 10^{3}$ & 116.2 & 2.31 \\
\hline \multicolumn{4}{|c|}{ Saturated aliphatic hydrocarbons } \\
\hline Decane & $52 \times 10^{-3}$ & 142.29 & 5.01 \\
\hline Dodecane & $3.7 \times 10^{-3}$ & 170.34 & 6.1 \\
\hline Hexadecane & $0.9 \times 10^{-3}$ & 226.45 & 8.25 \\
\hline \multicolumn{4}{|l|}{ Aromatic hydrocarbons } \\
\hline Toluene & 526 & 92.14 & 2.73 \\
\hline Dichlorobenzene & 156 & 147 & 3.43 \\
\hline \multicolumn{4}{|l|}{ Oil } \\
\hline Ethyl oleate & $579 \times 10^{-6}$ & 310.52 & 8.51 \\
\hline
\end{tabular}

\footnotetext{
${ }^{a}$ Data obtained from Handbook of Chemistry and Physics (Weast, 1972).
} 
(Giordano, 2001). The $\mathrm{pH}$ of the medium was adjusted to 7.5 by the automatic injection of $\mathrm{CO}_{2}$ and the temperature was maintained at $25^{\circ} \mathrm{C}$ by air blowing.

To investigate various biocompatibility assays, micro-algal cells were first cultivated in an airlift photobioreactor operated in continuous mode with standard growth conditions (with a continuous illumination ( $\left.200 \mu \mathrm{E} / \mathrm{m}^{2} \mathrm{~s}\right)$ by using four fluorescent tubes (SYLVANIA AQUASTAR F18W/174-T8)). Cells with a constant quality and quantity were thus obtained. To obtain cells enriched in $\beta$-carotene for extraction assays, the nitrate starvation has been applied (Mojaat et al., in press).

\subsection{Solvents}

Table 2 summarizes the solvents used in this study. They were selected according to their hydrophobicity $\left(\log P_{\text {oct }}\right)$ and their maximal solubility in water. The parameter $\log P_{\text {oct }}$ is defined as the partition coefficient of a given solvent in a mixture of octanol and water (Ogino et al., 1999), and the greater the polarity, the lower the $\log P_{\text {oct }}$ value of the solvent (Sardessai and Bhosle, 2002). The maximum solubilities and $\log P_{\text {oct }}$ values were found in the literature.

\subsection{Assays}

\subsubsection{Solvent biocompatibility assay}

In solvent toxicity experiments, $100 \mathrm{ml}$ of microalgae culture were incubated with $100 \mathrm{ml}$ of organic solvent for $15 \mathrm{~min}$ into a 500-ml Erlenmeyer flask and vigorously stirred $(800 \mathrm{rpm})$ to ensure the adequate contact between the solvent and the cells. After agitation, the photosynthetic activity was determined as indicated below.

\subsubsection{Critical solvent concentration assays}

To obtain a subsaturating solvent concentration as described by Vermuë et al. (1993), growth medium was first saturated with organic solvent by shaking the medium for $2 \mathrm{~h}$ with organic solvent and allowing phase separation at $30^{\circ} \mathrm{C}$. The solvent-saturated aqueous phase was then diluted with solvent-free growth medium. Microalgae cells were harvested by centrifugation and resuspended in the medium containing the desired solvent concentration. After vigorous stirring during $15 \mathrm{~min}$ of incubation the photosynthetic activity was determined.

\subsection{3. $\beta$-Carotene solubility assay}

Saturated solutions of $\beta$-carotene in the different organic solvents were obtained by adding amounts of $\beta$-carotene above the solubility limit to $5 \mathrm{ml}$ of each mixed organic solvents, stirring vigorously with a vortex during several minutes, followed by $2000 \mathrm{rpm}$ centrifugation during $10 \mathrm{~min}$ at $25^{\circ} \mathrm{C}$. After centrifugation and filtration through a syringe filter, the $\beta$-carotene content in saturated solutions was analyzed by HPLC as indicated below (León et al., 2003).

\subsection{4. $\beta$-Carotene extraction ability assay}

The ability of different mixed solvents to extract carotene from Dunaliella salina was estimated by incubating $10 \mathrm{ml}$ of microalgae culture, containing $24 \mathrm{pg} / \mathrm{cell}$ of $\beta$-carotene (stressed cells), with $10 \mathrm{ml}$ of the indicated mixed solvents and shaking at 500 rpm during $24 \mathrm{~h}$ at $25^{\circ} \mathrm{C}$, after while the $\beta$-carotene content in the organic phase was analyzed by HPLC.

\subsection{Analyses}

The $\beta$-carotene was analyzed by HPLC using a reversedphase $250 \mathrm{~mm} \times 4.6 \mathrm{~mm} \mathrm{C} \mathrm{C}_{30}$ column (YMC) and a tunable absorbance detector. The elution gradient was run as following: eluent $\mathrm{A}\left(81 \% \mathrm{MeOH}, 15 \% \mathrm{MTBE}\right.$ and $\left.4 \% \mathrm{H}_{2} \mathrm{O}\right)$, eluent B $\left(6 \% \mathrm{MeOH}, 90 \%\right.$ MTBE and $\left.4 \% \mathrm{H}_{2} \mathrm{O}\right) ; 100 \%$ A to $100 \% \mathrm{~B}$ in $90 \mathrm{~min}$. The flow rate was $1 \mathrm{ml} \mathrm{min}^{-1}$. The detection wavelength was $450 \mathrm{~nm}$. Standard of $\beta$-carotene was purchased from SIGMA-ALDRICH.

Photosynthetic activity was used as an indicator of cells viability. It was assessed by the pulse-amplitude modulated (PAM) fluorescence using the WATER-PAM fluorometer (WALZ, Germany) via measurement of light-induce of changes in fluorescence to measure the quantum yield of PSII photochemistry $\left(\Delta F_{\mathrm{v}} / F_{\mathrm{m}}^{\prime}\right)$.

\section{Results and discussion}

\subsection{Predicting biocompatibility in the presence of pure organic solvents}

\subsubsection{Solvent toxicity}

The effect of water-immiscible organic solvents on photosynthetic activity in Dunaliella salina was determined by measuring the photosynthetic activity in the presence of $50 \%(\mathrm{v} / \mathrm{v})$ of each solvent. In an attempt to find a correlation between the physicochemical properties and the toxicity of the solvents, solvent properties such as the molecular size (as expressed by the molecular weight) and an estimation of the polarity such as $\log P_{\text {oct }}$ were correlated to the photosynthetic activity in presence of the specific solvent (activity expressed as the ratio between remaining activity, and the activity in absence of solvent).

Plotting the activity of Dunaliella salina against hydrophobicity of the solvent $\left(\log P_{\text {oct }}\right)$, a sharp sigmodial variation is obtained (Fig. 1a). Shape of this curve has already been observed for other microalgae, plant and bacteria (León et al., 1998). These results indicate that solvent having a $\log P_{\text {oct }}$ lower than 3 are relatively polar solvents not suitable for metabolic activity, and that biological activities vary in solvents having a $\log P_{\text {oct }}$ between 3 and 5. In apolar solvents having $\log P_{\text {oct }}$ values above 5 , metabolic activity is not affected and in some cases it was even higher than in absence of solvent. The permeability effect of the solvent on cell membrane enhances substrate and product transport into/from the cellular cytoplasm which explains the increase of the photosynthetic rates observed in some cases (Flores et al., 1994; León et al., 1998, 2001). Laane et al. (1987) concluded that excluding the transition region where the inflexion point is located, a solvent that has a $\log P_{\text {oct }}$ value lower 

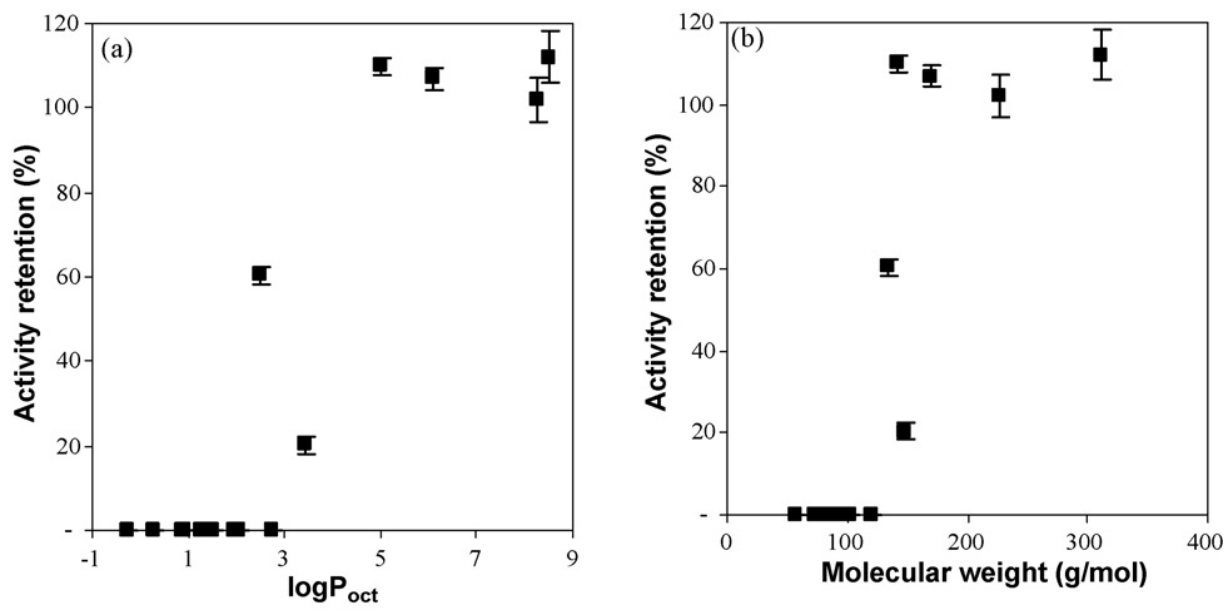

Fig. 1. Relationship between activities retention of Dunaliella salina cells exposed to an organic solvent and the $\log P_{\text {oct }}$ value of the solvent (a) and its molecular size (b).

than the inflexion point is usually toxic and a solvent that has a $\log P_{\text {oct }}$ value higher than the inflexion point is usually biocompatible. León et al. (1998) have shown that the location of the inflexion point is dependent on the type of organism, probably due to differences in cell wall structures. Hejazi et al. (2002) and León et al. (2001) have studied the toxicity of alkane and alcohol solvents in Dunaliella salina. They found a similar general response, although their curve is shifted to the left. This shift could be due to differences in the solvent series used in each case.

Brink and Tramper (1985) attempted to relate the observed increasing toxicity of pure solvents with their decreasing molecular weights. As they showed, only solvents which have a molecular weight over $150 \mathrm{~g} / \mathrm{mol}$ are generally applicable for bioorganic synthesis (Fig. 1b), by supposing that a critical volume of solvent in the membrane is the cause of lysis of the cells. This theory would suggest that smaller molecules should have greater concentrations in the membrane as compared to large molecules (Osborne et al., 1990), so that this is not the critical volume but the critical concentration of solvent which causes the toxicity. Therefore, to predict the biocompatibility of the solvents and for a rational selection, it is important to establish the critical solvent concentration in the membrane of Dunaliella salina. The determination of the critical solvent concentration for the series of chloro, ether, ketone and alcohol compounds, for which we have showed their total toxicity previously, is then the next step in the understanding of the interaction between cells and solvent.

\subsubsection{Determination of critical solvent concentration in the membrane}

The primary action site of organic solvents is the cell membrane. This cytoplasmic membrane plays a vital role in solute transport, maintaining the energy status of the cell and the regulation of the intracellular environment (Sardessai and Bhosle, 2002; Weber and de Bont, 1996). Therefore the toxicity for cells is mainly attributed to a distorting action on the cell membrane and membrane-linked enzymes due to the partition of solvents into the lipid bilayer causing their disruption and compromising the cell viability (Sikkema et al., 1995). It has been proved that it is not the chemical structure of the solvent, but the concentration to which it accumulates in the cell membrane, that plays a crucial role in determining toxicity (De Bont, 1988; Sikkema et al., 1992).

Generally, the solvent toxicity in an organic-aqueous twoliquid phase system is caused both by the presence of the second phase (phase toxicity), and by the solvent molecules that dissolve in the aqueous phase (molecular toxicity) (Bar, 1988). The phase toxicity is encountered when enough solvent is present to form a separate phase. In this case, the cell is in direct contact with the solvent phase where the solvent could block nutrient diffusion, disrupt the cell wall and cause extraction of inner cellular components (Vermuë et al., 1993). The molecular toxicity describes the effect of a solvent when it is dissolved in the aqueous phase at levels below saturation (Bruce and Daugulis, 1991). The lipid membranes of the cell absorb some of the dissolved solvent that can induce a modification of the membrane permeability, resulting in enzyme inhibition, protein deactivation, or a breakdown of transport mechanisms. Hocknull and Lilly have suggested that biocatalytic activity may be lost, in the absence of phase solely through sufficient dissolved aqueous phase solvent partitioning into the cell (Laane et al., 1987). Therefore, as Bassetti and Tramper (1994), we have thereafter used solvents at subsaturation levels to separate the effects of molecular toxicity from those of phase toxicity.

Various analytical techniques, including X-ray diffraction and various magnetic resonance spectroscopy methods (NMR and EPR), have been employed to determine the dose-response relationship of solvent in membrane (Weber and de Bont, 1996). These different techniques reveal similar tendencies, supporting the view that the actual solvent concentration in the membrane depends on the concentration of solvent in the water phase, and on the partitioning of the solvent from the water phase to the membrane (Sikkema et al., 1994). Osborne et al. (1990) defined the critical solvent concentration in the membrane as the concentration of solvent in the cell membrane that causes complete loss of activity, independent of the solvent type. For a given solvent, the partition coefficient $\left(P_{\text {mem }}\right)$ between the membrane and the 


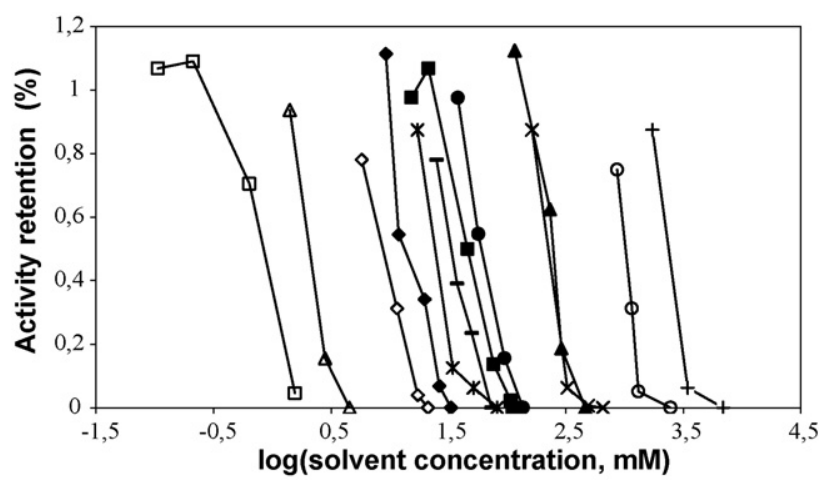

Fig. 2. Activity retention (\%) of Dunaliella salina as a function of the logarithm of solvent concentration in the aqueous phase. D. salina cells were incubated in the presence of chloroform $(\checkmark)$, dichloromethane $(\boldsymbol{\square})$, trichloroethane $(\square)$, acetone $(+)$, methyl ethyl ketone $(\bigcirc)$, methyl isobutyl ketone $(\boldsymbol{O})$, methyl tertbutyl ether $(\boldsymbol{\Delta})$, diethyl ether $(\times)$, di-isopropyl ether $(*)$, pentanol $(-)$ heptanol $(\triangle)$ and hexanol $(\diamond)$.

aqueous phase is related to $P_{\text {oct }}$ via Collander-type relationship:

$P_{\text {mem }}=\frac{[\mathrm{solv}]_{\mathrm{mem}}}{[\mathrm{solv}]_{\mathrm{aq}}}$

$P_{\mathrm{mem}}=R \times P_{\mathrm{oct}}^{\mathrm{A}}$

where $R$ is the partition coefficient of the solvent over an hypothetical membrane/octanol system and is assumed to be constant for all solvents (Vermuë et al., 1993). Osborne et al. (1990) have assumed that $R$ has a value of 0.19 . The exponent $\mathrm{A}$ accounts for the deviation between the solvent-membrane interactions and the solvent-octanol interaction. Rewriting Eqs. (1) and (2), the following relationship can be deduced between the critical aqueous phase concentration of each solvent, which causes a total loss of activity ([solv $\left.\left.\mathrm{aq}_{\mathrm{aq}, \mathrm{cr}}\right]\right)$, and the corresponding critical solvent concentration in the membrane $\left(\left[\operatorname{solv}_{\mathrm{mem}, \mathrm{cr}}\right]\right)$ :

$\log \left([\mathrm{solv}]_{\mathrm{aq}, \mathrm{cr}}\right)=\log \left(\frac{[\mathrm{solv}]_{\mathrm{mem}, \mathrm{cr}}}{R}\right)-A \log P_{\mathrm{oct}}$

For critical aqueous solvent concentration determination, microalgae were incubated in growth medium with different concentrations of solvent, and the photosynthetic activity was determined after 15 min of incubation. The aqueous solvent concentration at which the photosynthetic activity becomes zero was considered as the critical aqueous solvent concentration (the $x$-intercept in Fig. 2).

Plotting $\log \left(\left[\right.\right.$ solv $\left.\left._{\mathrm{aq}, \mathrm{cr}}\right]\right)$ against $\log P_{\mathrm{oct}}$ for several solvents, a negative linear function is obtained (Fig. 3). We can observe that the critical concentration of polar solvents (low $\log P_{\mathrm{oct}}$ ) is higher than the critical concentration of more hydrophobic ones and that Dunaliella salina is thus able to withstand higher concentrations of polar solvents. For example, the critical aqueous acetone concentration $\left(\log P_{\text {oct }}=-0.24\right)$ is $6887 \mathrm{mM}$, while the critical aqueous heptanol concentration $\left(\log P_{\mathrm{oct}}=2.31\right)$ is $4.5 \mathrm{mM}$. So, the solvent that has a high $\log P_{\text {oct }}$ value has a high affinity to partition into the lipid bilayer (Bassetti and Tramper, 1994). It must be noticed that very hydrophobic solvents are toxic (Vermuë and Tramper, 1995). This seems to be in contrast with the general observation that solvents with high $\log P_{\text {oct }}$ are less toxic to cells. However, hydrophobic solvents like decane generally exhibit such low solubility in water that the threshold concentration that would cause molecular toxicity effects cannot be reached (León et al., 2001).

Osborn's model (Eq. (3)) is applied to the four series of solvents. The slope of the line represents $\mathrm{A}$ and its intercept is the logarithm of the critical membrane concentration divided by $R$. Osborne et al. (1990) assumed a constant value of 0.19 for $R$, to estimate a single value for critical membrane concentration. Regressions were made using all data, but also for solvents of a same family. Parameters obtained from the linear regression analysis of experimental data, and critical solvent membrane concentration values are summarized in Table 4 , assuming a value of $R=0.19$.

The value of $[\mathrm{solv}]_{\mathrm{mem}, \mathrm{cr}}$ differs for different solvent series and is constant for all the solvents within one homologous series, a results similar to that have been obtained by Bassetti and Tramper (1994).

The critical alcohol membrane concentration is higher than the value reported by León et al. (2001). It is necessary to note that small standard deviations in the $y$-intercept mean large deviations in the critical solvent membrane concentration values. Moreover, Sikkema et al. (1995) showed that the distribution ratio of the solvent between the membrane and the aqueous phase depends not only on simple partitioning but also on differences in environmental conditions (e.g., $\mathrm{pH}$, temperature...), causing large variations in the distribution of the molecules. In addition, Osborne et al. (1990) have shown that for some solvents the value of $R$ may be quite different, reflecting some hypo- or hyper-discriminative power of the membrane towards certain types of molecules. Vermuë et al. (1993) showed that ([solv $\left.]_{\mathrm{mem}, \mathrm{cr}} / R\right)$ is constant for both alkanols and acetates and if therefore the $[\mathrm{solv}]_{\mathrm{mem}, \mathrm{cr}}$ changes, $R$ thus has to change in an identical manner.

Nevertheless, a good correlation between the critical aqueous solvent concentration $[\mathrm{solv}]_{\mathrm{aq}, \mathrm{cr}}$ and the partition coefficients octanol/water two-phase systems has been observed (Fig. 3). The

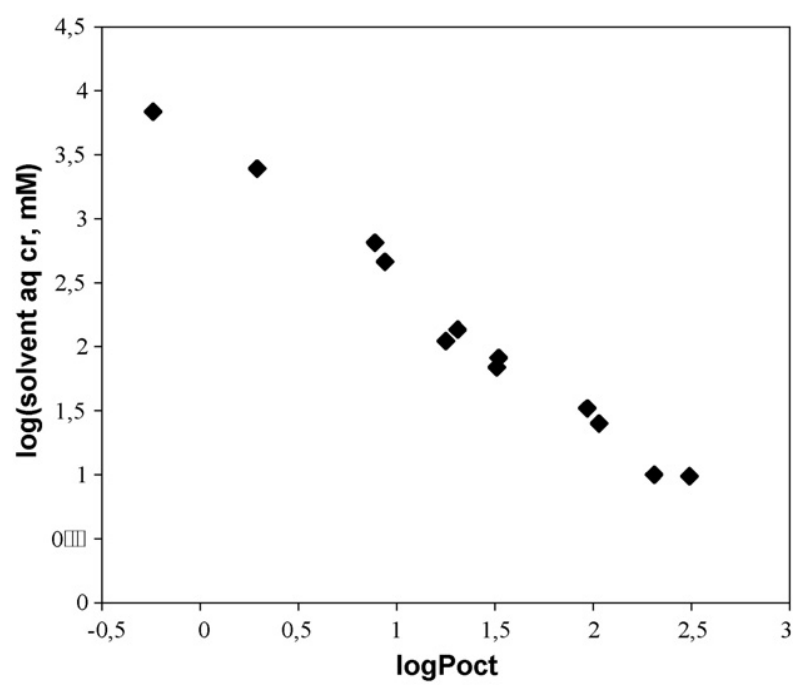

Fig. 3. Relationship between the logarithm of the critical aqueous solvent concentration $[\mathrm{solv}]_{\mathrm{aq}, \mathrm{cr}}$ and the $\log P$ value of solvents for Dunaliella salina. 
Table 3

Critical membrane concentration values and regression analysis parameters for data presented in Fig. 3

\begin{tabular}{|c|c|c|c|c|c|}
\hline & All solvents & Alcohols & Ethers & Chlorinated & Ketones \\
\hline Slope & 1.034 & 1.024 & 1.373 & 0.861 & 1.117 \\
\hline$y$-Intercept & 3.588 & 3.41 & 3.997 & 3.154 & 3.627 \\
\hline Corr. coef. $\left(R^{2}\right)$ & 0.98 & 0.98 & 0.99 & 0.99 & 0.99 \\
\hline$[\mathrm{solv}]_{\mathrm{mem}, \mathrm{cr}}(\mathrm{mM})($ if $R=0.19)$ & 736 & 490 & 1887 & 271 & 806 \\
\hline
\end{tabular}

results shown in Table 3 for Dunaliella salina can thus be considered reliable. The Osborn model together with these results would be very useful for assessing toxicity hazards of chemicals and for predicting the biocompatibilty of pure solvents.

These calculated concentrations are listed in Table 4. We can see that the amount of solvent dissolved in water and in the cellular membrane decreases with increasing solvent hydrophobicity $\left(\log P_{\mathrm{oct}}\right)$ for the homologous solvent series. It is also shown that the aliphatic chlorinated hydrocarbon is the most toxic studied family.

This increased knowledge of the toxic action of solvents can be used for solvent selection in the same way as the $\log P_{\text {oct }}$ and the molecular weight but with greater insight into the mechanisms involved. If the aqueous solubility of a solvent is known and if its $\log P_{\text {oct }}$ value can be calculated, then Eq. (3) can be used to determine the maximum concentration the solvent can reach in the cell membrane, as well as the critical aqueous concentration for any solvents. So, if the critical solvent concentration cannot be reached, the solvent will not show toxicity. Therefore, the solvents which are unable to reach the critical membrane concentration (this is the case of decane) can be considered as biocompatible.

This previous discussion has focused on prediction and selection techniques for pure (single) solvents. Clearly, a significant progress could be made in this area through the use of this strategy (Osborne et al., 1990; Vermuë et al., 1993; Bassetti and Tramper, 1994; León et al., 1998), to determine solvent biocompatibility in two-liquid-phase systems. Biocompatible solvents, however, tend to possess chemical characteristics that make them poor extractants. This justifies the motivation to look for more effective extractants by using mixed solvents, which is strengthened by the fact that product extraction with a more effective extractant requires a smaller volume to extract the product (Bruce and Daugulis, 1991). Thus, in order to test the efficiency of extraction of mixtures of solvents, we have studied mixtures of decane, as a biocompatible solvent, with dichloromethane, methyl ethyl ketone or methyl tert-butyl ether, as toxic solvents.

\subsection{Mixtures of organic solvents}

It has been suggested that a biocompatible but poor solvent of the target compound could be mixed with a toxic or inhibitory solvent that has a better extracting capability, to yield a mixture with improved solvent characteristics and still biocompatible. As for pure solvents, a solvent mixture could still be biocompatible if the concentration of the toxic solvent in the aqueous phase is lower than the aqueous critical solvent concentration (Evans and Wang, 1988). This aspect has thus been investigated in the following part.

\subsubsection{Predicting biocompatibility of mixed solvents}

Fig. 4 shows the biocompatibility of mixed solvents as a function of $\% V_{\text {toxic solvent }} / V_{\text {organic phase }}$, the ratio between the volume of toxic solvent and volume of organic phase (total volume of biocompatible and toxic solvents). The biocompatibility of the mixed solvents was calculated by dividing the average activity of the cells in the presence of mixed solvents by their average activity after addition of decane (which is biocompatible). The dichloromethane $\left(\mathrm{CH}_{2} \mathrm{Cl}_{2}\right)$ is the most toxic solvent (Fig. 4). As we have previously shown (Table 4), the most biocompatible solvent studied, where Dunaliella salina had the highest critical solvent membrane concentration value, is methyl tertbutyl ether (MTBE), followed by methyl ethyl ketone (MEK) and dichloromethane $\left(\mathrm{CH}_{2} \mathrm{Cl}_{2}\right)$. Moreover, by calculating the critical aqueous concentration of toxic solvents, we observed that the critical aqueous concentration of $\mathrm{CH}_{2} \mathrm{Cl}_{2}, \mathrm{MTBE}$ and MEK in respective mixtures: decane- $\mathrm{CH}_{2} \mathrm{Cl}_{2}$, decane-MTBE and decane-MEK, is higher than the critical aqueous concentration of pure solvents (Table 5). These results agree with Bruce and Daugulis (1991) who have shown that mixed solvents were less toxic. So the transition region between full biocompatibility and toxicity was enlarged. The addition of a biocompatible solvent to a toxic solvent in a two-liquid phase system results in a decrease of the real concentration of the

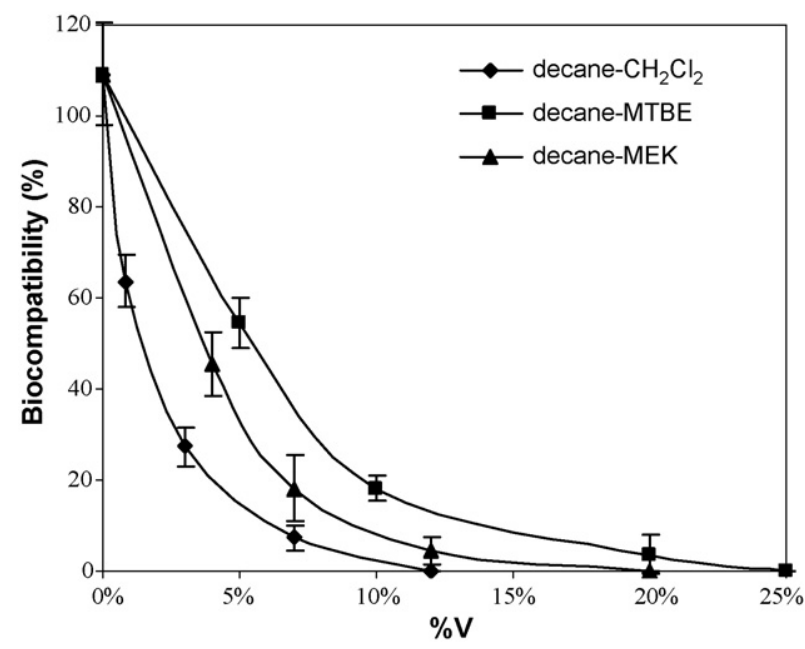

Fig. 4. Activity retention (\%) of Dunaliella salina as a function of $V_{\text {toxic solvent }} / V_{\text {organic phase }} D$. salina cells were incubated in the presence of mixed solvents decane- $\mathrm{CH}_{2} \mathrm{C}_{2}$, decane-MEK and decane-MTBE. 
Table 4

Maximum achievable membrane solvent concentration, calculated from the membrane partition coefficient and the maximum water solubility (Eq. (1))

\begin{tabular}{|c|c|c|c|c|c|}
\hline Solvent & $\log P_{\text {oct }}$ & $\log P_{\mathrm{mem}}$ & Max. aqueous solubility (mM) & Max. membrane conc. (mM) & {$[\mathrm{solv}]_{\mathrm{mem}, \mathrm{cr}}(\mathrm{mM})$} \\
\hline \multicolumn{6}{|c|}{ Aliphatic chlorinated hydrocarbons } \\
\hline Dichloromethane & 1.25 & 0.35 & 153 & 344 & 271 \\
\hline Chloroform & 1.97 & 0.97 & 66 & 318 & 271 \\
\hline Trichloroethane & 2.49 & 1.41 & 9.6 & 252 & 271 \\
\hline \multicolumn{6}{|l|}{ Aliphatic ethers } \\
\hline Diethyl ether & 0.89 & 0.5 & 814 & 2579 & 1887 \\
\hline Methyl tert-butyl ether & 0.94 & 0.57 & 578 & 2147 & 1887 \\
\hline Di-isopropyl ether & 1.52 & 1.36 & 86 & 2000 & 1887 \\
\hline \multicolumn{6}{|l|}{ Aliphatic ketones } \\
\hline Acetone & -0.24 & -0.99 & 17217 & 1764 & 806 \\
\hline Methyl ethyl ketone & 0.29 & -0.39 & 3092 & 1239 & 806 \\
\hline Methyl isobutyl ketone & 1.31 & 0.74 & 189 & 1048 & 806 \\
\hline \multicolumn{6}{|l|}{ Aliphatic alcohols } \\
\hline Pentanol & 1.51 & 0.82 & 249 & 1669 & 490 \\
\hline Hexanol & 2.03 & 1.35 & 57 & 1316 & 490 \\
\hline Heptanol & 2.31 & 1.64 & 28 & 1242 & 490 \\
\hline
\end{tabular}

toxic solvent dissolved in the aqueous phase. It was argued that if the toxicity of some solvents is dependent upon its concentration in aqueous solution, then, in accordance with Henry's and Raoult's laws, the addition of a non-toxic compound with a toxic miscible one would relieve the toxic effect by decreasing the vapour pressure of the toxic solvent and hence its concentration in aqueous phase (Gill and Ratledge, 1972). Indeed, it has been clearly demonstrated that the addition of the correct non-toxic solvent will certainly reduce or negate the effects of a toxic solvent present in the biphasic system (Bruce and Daugulis, 1991; Salter and Kell, 1992). So if we establish the ternary diagram (toxic solvent-biocompatible solvent-water) we can calculate the concentration of the toxic solvent which can be added to mixed solvent for a biocompatible extraction. This concentration must be lower than the aqueous critical solvent concentration determined by applying the Osborne model.

\subsubsection{Solubility of $\beta$-carotene in mixed solvents}

To have a global view of the properties of different mixed solvents, we have determined the solubility of commercial $\beta$ carotene in these mixtures by plotting the logarithm of the maximum solubility of carotene in the mixed solvents against the volume percentage of the toxic solvent. A positive linear function is obtained (Fig. 5). We observed that the solubility of $\beta$-carotene is higher in the mixture decane- $\mathrm{CH}_{2} \mathrm{Cl}_{2}$.

Table 5

Aqueous critical concentration of solvent in the case of pure solvents and mixed solvents was calculated respectively from Figs. 2 and 4

\begin{tabular}{lcc}
\hline Toxic solvent & $\begin{array}{l}{[\text { solv }]_{\mathrm{aq}, \text { cr of pure }}} \\
\text { solvent }(\mathrm{mM})\end{array}$ & $\begin{array}{l}{[\text { solv }]_{\mathrm{aq}, \text { cr of mixed }}} \\
\text { solvent }(\mathrm{mM})\end{array}$ \\
\hline Dichloromethane & 176 & 7545 \\
MTBE & 462 & 13442 \\
MEK & 2462 & 13326 \\
\hline
\end{tabular}

\subsubsection{Ability of extraction}

Vermuë et al. (1993) defined the solvent as toxic if the metabolic activity of the cell was less than $50 \%$ of the metabolic activity of the cell in the absence of the solvent. Therefore, in order to test the efficiency of these mixed solvents, we have fixed the volume of the toxic solvent by keeping a minimum threshold of $50 \%$ of photosynthetic activity (Fig. 4). So the concentrations of $\mathrm{CH}_{2} \mathrm{Cl}_{2}, \mathrm{MEK}$ and MTBE which have been added to the mixture are respectively $190 \mathrm{mM}, 335 \mathrm{mM}$ and $420 \mathrm{mM}$. Fig. 6 shows the ability of extraction for the different mixed solvents. We observed that the $\beta$-carotene solubility has an important impact on the extraction ability of the solvent (Fig. 6). Therefore the mixture $\mathrm{CH}_{2} \mathrm{Cl}_{2}$-decane is able to extract $\beta$-carotene six times more efficiently than the pure decane (Fig. 6). Also, this result can be due to the increase in the permeability effect of the mixed solvents on cell membrane caused by the addition of dichloromethane. Indeed, the concentration of the solvent accumulated in the cell membrane will be increased in the case of mixed solvent compared to case of

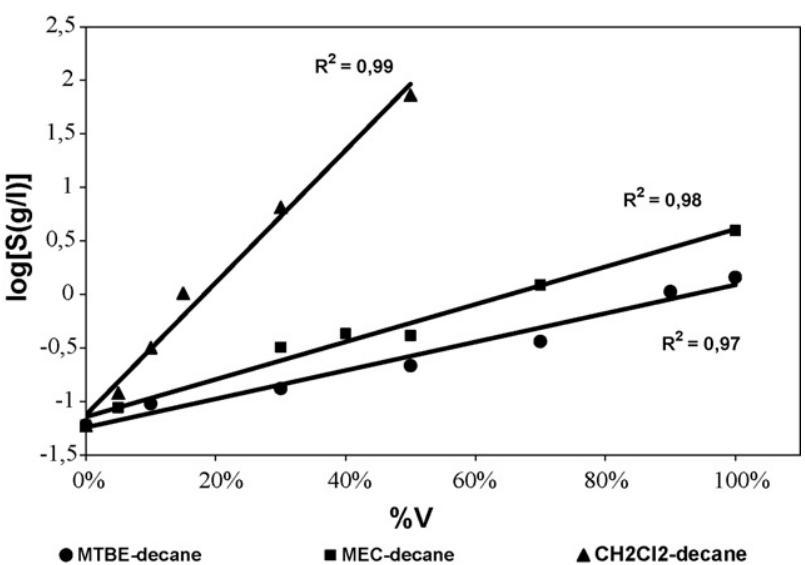

Fig. 5. Solubility of $\beta$-carotene in mixed solvents decane- $\mathrm{CH}_{2} \mathrm{Cl}_{2}$, decane-MEK and decane-MTBE as a function of the $V_{\text {toxic solvent }} / V_{\text {organic phase }}$. 


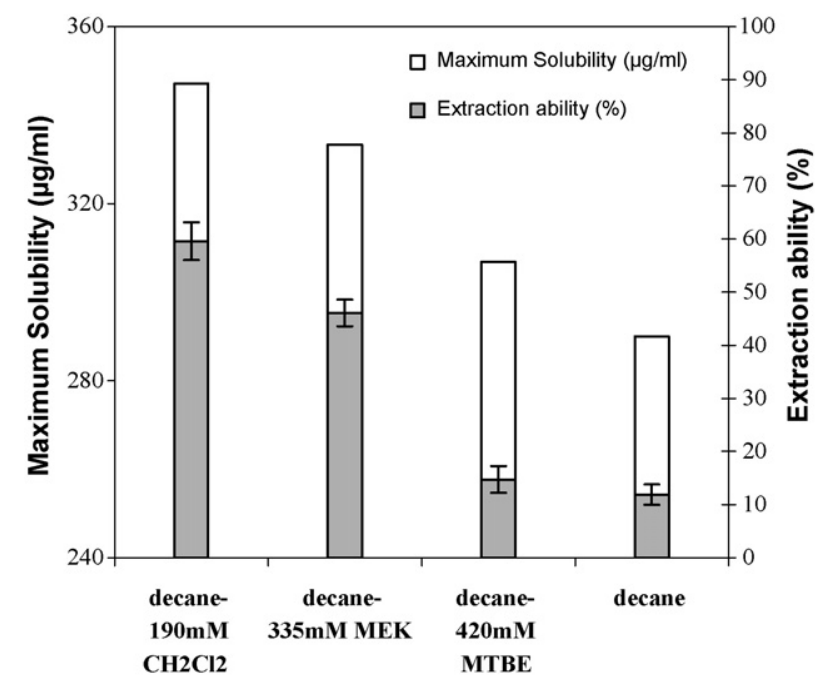

Fig. 6. Extraction ability (\%) of different mixed solvents and decane on Dunaliella salina and solubility of $\beta$-carotene in these solvents.

pure decane, thus showing interest of using mixed solvent. This conclusion can be completed by that of Hejazi et al. (2004), which gave further explanation of the role of dissolved solvent in the cell membrane in the extraction process of $\beta$-carotene at the intracellular scale. They suggested two possible modes of extraction of $\beta$-carotene from Dunaliella salina: The solvent is dissolved in the cell membrane and is taken up by the cells into the space between cell membrane and chloroplast membrane by diffusion. This leads to more activity in the membranes and to more active endo- and exo-cytosis (Zhang et al., 1993). As a result the $\beta$-carotene globules are transported from the chloroplast to the space between the cell and the chloroplast membrane and from there to the outside by exocytosis. Another mode suggests that the solvent dissolves the $\beta$-carotene from the oil globules. So, the solubilized $\beta$-carotene molecules diffuse from the chloroplast to space between the cell and the chloroplast membranes and from there to the outside. So the ability of extraction does not depend solely on affinity of solvent with the product extracted but also on its concentration incorporated in the cellular membrane, thus showing interest of the addition of a toxic solvent in appropriate quantity. Therefore the new strategy of solvent selection for biocompatible extraction of $\beta$-carotene is based on two requirements: biocompatibility of the mixed solvents which can be estimated by applying the Osborn model and a sufficient solubility of $\beta$-carotene in the chosen mixed solvent.

\section{Conclusion}

As found for other microorganisms, $\log P_{\text {oct }}$ and molecular weight are good indicators for the choice of pure biocompatible solvents. Only the solvents which have a $\log P_{\text {oct }}$ value higher than 5 or molecular weight higher than $150 \mathrm{~g} / \mathrm{mol}$, are applicable for biocompatible extraction of $\beta$-carotene from Dunaliella salina. Yet, for more rational selection of biocompatible solvent, the membrane critical solvent concentration for the series of chloro, ether, ketone and alcohol compounds was calculated by applying Osborne's model where prediction of the toxicity of any given solvent in two-liquid-phase system using Dunaliella salina became possible to a certain extent.

Testing the efficiency of extraction of mixtures of solvents, we showed that the mixture of a highly apolar solvent (such as decane) with a more polar one $\left(\mathrm{CH}_{2} \mathrm{Cl}_{2}, \mathrm{MEK}\right)$ combines the desirable properties of each: few volume of polar solvent has allowed a better extraction of $\beta$-carotene, while polar organic solvent became biocompatible when added with the biocompatible solvent (decane). However, the selection of polar solvent is complicated. The toxic coextractant can be chosen by employing as criterion both solubility of $\beta$-carotene in this solvent and its concentration accumulated in cell membrane. So the determination of the critical membrane concentration of toxic solvent in the case of mixed solvents remains to be studied, as well as, intracellular mechanisms (transport, extraction and various metabolic influences) which would have to be clarified.

\section{References}

Bar, R., 1988. Effect of interphase mixing on a water-organic solvent two-liquid phase microbial system: ethanol fermentation. J. Chem. Technol. Biotechnol. 43, 49-62.

Bassetti, L., Tramper, J., 1994. Organic solvent toxicity in Morinda citrifolia cell suspensions. Enzyme Microb. Technol. 16, 642-648.

Ben-Amotz, A., 1995. New mode of Dunaliella biotechnology: low-phase growth for $\beta$-carotene production. J. Appl. Phycol. 7, 65-68.

Ben-Amotz, A., 1982. Accumulation of $\beta$-carotene in halotolerant algae: purification and characterization of $\beta$-carotene-rich globules from Dunaliella bardawil (Chlorophyceae). J. Phycol. 18, 529-537.

Borowitzka, M.A., 1999. Commercial production of microalgae: ponds, tanks, tubes and fermenters. J. Biotechnol. 70, 313-321.

Brink, L.E.S., Tramper, J., 1985. Optimization of organic solvent in multiphase biocatalysis. Biotechnol. Bioeng. 27, 1258-1269.

Bruce, L.J., Daugulis, A.J., 1991. Solvent strategies for extractive biocatalysis Biotechnol. Prog. 7, 116-124.

Choi, W.J., Choi, C.Y., De Bont, J.A.M., Weijers, C.A.G.M., 2000. Continuous production of enantiopure 1,2-expoxyhexane by yeast epoxide hydrolase in a two-phase membrane bioreactor. Appl. Microbiol. Biotechnol. 54, 641-646.

Daugulis, A.J., 1988. Integrated reaction and product recovery in Bioreactor systems. Biotechnol. Prog. 4, 113-122.

De Bont, J.A.M., 1988. Solvent-tolerant bacteria in biocatalysis. Focus 16 , 493-499.

Dufossé, L., Galaup, P., Yaron, A., Arad, S.M., Blanc, P., Kotamballi, N., Murthy, C., Ravishankar, G.A., 2005. Microorganisms and microalgae as sources of pigments for food use: a scientific oddity or and industrial reality? Trends Food Sci. Technol. 16, 389-406.

Evans, P.J., Wang, H.Y., 1988. Response of Clostridium acetobutylicum to the presence of mixed extractants. Appl. Biochem. Biotechnol. 16, 113-122.

Flores, M.V., Voget, C.E., Ertola, R.J.J., 1994. Permeabilization of yeast cells (Kluyveromyces lactis) with organic solvents. Enzyme Microb. Technol. 16, 340-346.

Gill, C.O., Ratledge, C., 1972. Toxicity of $n$-alkanes, $n$-alk-1-enes, $n$-alkan-1-ols and $n$-alkyl-1-bromides towards yeasts. J. Gen. Microbiol. 72, 165-172.

Giordano, M., 2001. Interactions between $\mathrm{C}$ and $\mathrm{N}$ metabolism in Dunaliella salina cells cultured at elevated $\mathrm{CO}_{2}$ and high $\mathrm{N}$ concentrations. J. Plant Physiol. 158, 577-581.

Hejazi, M.A., Kleinegris, D., Wijffels, R.H., 2004. Mechanism of extraction of $\beta$-carotene from microalga Dunaiella salina in two-phase bioreactors. Biotechnol. Bioeng. 88, 593-600.

Hejazi, M.A., Holwerda, E., Wijiffels, R.H., 2003. Milking microalga Dunaliella salina for $\beta$-carotene production in two-phase bioreactors. Biotechnol. Bioeng. $85,475-481$. 
Hejazi, M.A., Wijffels, R.H., 2003. Effect of light intensity on $\beta$-carotene production and extraction by Dunaliella salina in two-phase bioreactors. Biomol. Eng. 20, 171-175.

Hejazi, M.A., de Lamarliere, C., Rocha, J.M.S., Vermuë, M., Tramper, J., Wijffels, R.H., 2002. Selective extraction of carotenoids from the alga Dunaliella salina with retention of the viability. Biotechnol. Bioeng. 79, 29-36.

Laane, C., Boeren, S., VOS, K., Veeger, C., 1987. Rules for the optimization of biocatalysis in organic solvents. Biotechnol. Bioeng. 30, 81-87.

León, R., Martín, M., Vigara, J., Vilchez, C., Vega, J.M., 2003. Microalgae mediated photoproduction of $\beta$-carotene in aqueous-organic two phase systems. Biomol. Eng. 20, 177-182.

León, R., Garbayo, I., Hernández, R., Vigara, J., Vilchez, C., 2001. Organic solvent toxicity in photoautotrophic unicellular microorganisms. Enzyme Microb. Tech. 29, 173-180.

León, R., Fernandes, P., Pinheiro, H.M., Cabral, J.M.S., 1998. Whole-cell biocatalysis in organic media. Enzyme Microb. Tech. 23, 483-500.

Metting Jr., F.B., 1996. Biodiversity and application of microalgae. J. Ind Microb. Biot. 17, 477-489.

Mojaat, M., Pruvost, J., Foucault, A., Legrand, J. Effect of organic carbon sources and $\mathrm{Fe}^{2+}$ ions on growth and $\beta$-carotene accumulation by Dunaliella salina. Biochem. Eng. J., in press.

Ogino, H., Miyamoto, K., Yasuda, M., Ishimi, K., Ishikawa, H., 1999. Growth of organic solvent-tolerant Pseudomonas aeruginosa LST-03 in the presence of various organic solvents and production of lipolytic enzyme in the presence of cyclohexane. Biochem. Eng. J. 4, 1-6.

Osborne, S.J., Leaver, J., Turner, M.K., Dunnill, P., 1990. Correlation of biocatalytic activity in an organic-aqueous two-phase system with solvent concentration in the cell membrane. Enzyme Microb. Tech. 12, 281-291.

Raja, R., Hemaiswarya, S., Rengasamy, R., 2007. Exploitation of Dunaliella for $\beta$-carotene production. Appl. Microbiol. Biotechnol. 74, 517-523.

Salter, G.J., Kell, D.B., 1992. Rapid determination, using dielectric spectroscopy, of the toxicity of organic solvents to intact cells. In: Tremper,
J., Vermüe, M.H., Beeftink, H.H., von Stockar, U. (Eds.), Biocatalysis in Non-Conventional Media. Elsevier, Amsterdam, pp. 291-297.

Santhanam, H.K., Shreve, G.S., 1994. Solvent selection and productivity in multiphase biotransformation systems. Biotechnol. Prog. 10, 187-192.

Sardessai, Y., Bhosle, S., 2002. Tolerance of bacteria to organic solvents. Res. Microbiol. 153, 263-268.

Sikkema, J., De Bont, J., Poolman, B., 1995. Mechanisms of solvent toxicity of hydrocarbons. Microbiol. Rev. 59, 201-222.

Sikkema, J., De Bont, J.A.M., Poolman, B., 1994. Interactions of cyclic hydrocarbons with biological membranes. J. Biol. Chem. 269, 80228028.

Sikkema, J., Poolman, B., Konings, W.N., De Bont, J.A.M., 1992. Effects of the membrane action of tetralin on the functional and structural properties of artificial and bacterial membranes. J. Bacteriol. 174, 2986-2992.

Vermuë, M., Tramper, J., 1995. Biocatalysis in non-conventional media: medium engineering aspects. Pure Appl. Chem. 67, 345-373.

Vermuë, M., Sikkema, J., Verheul, A., Bakker, R., Tramper, J., 1993. Toxicity of homologous series of organic solvent for the Gram-positive bacteria Arthrobacter and Nocardia sp. and the Gram-negative bacteria Acinetobacter and Pseudomonas sp. Biotechnol. Bioeng. 42, 747-758.

Weber, F.J., de Bont, J.A.M., 1996. Adaptation mechanisms to the toxic effects of organic solvents on membranes. Biochim. Biophys. Acta 1286, 225245.

Weast, R.C. (Ed.), 1972. Handbook of Chemistry and Physics. The Chemical Rubber Co., Ohio.

Xu, Q.M., Heng, J.S., Ge, Z.Q., Yuan, Y.J., 2004. Effects of organic solvents on membrane of Taxus cuspidata cells in two-liquid-phase cultures. Plant cell. Tiss. Org. Culture 79, 63-69.

Zhang, X.Q., Dubacq, J., Alfsen, A., 1993. Biochemical and cytological evidence for the stimulation of clathrin-coated pit (vesicle) formation by exogenous folic acid in Dunaliella salina. J. Phycol. 29, 203-209. 